\title{
Short communication: Pharmacokinetics of intramammary hetacillin in dairy cattle milked 3 times per day
}

\author{
Danielle A. Lindquist, Ronald E. Baynes, and Geof W. Smith ${ }^{1}$ \\ Department of Population Health and Pathobiology and the Food Animal Residue Avoidance Depletion Program, College of Veterinary Medicine, \\ North Carolina State University, Raleigh 27607
}

\begin{abstract}
Mastitis remains a critical disease in the dairy industry and the use of intramammary antibiotics plays a critical role in mastitis treatment. Hetacillin is currently approved as an intramammary antibiotic that is used to treat mastitis in dairy cows. It is approved for once a day administration and can be used for a total of $3 \mathrm{~d}$. An increasing number of dairy farms are milking 3 times per day (instead of the traditional 2 times per day) and very little pharmacokinetic data exists on the use of intramammary drugs in a $3 \times$ system. The primary purpose of this study was to determine if once a day intramammary infusion of hetacillin is sufficient to maintain therapeutic drug concentrations in cattle milked 3 times per day. Eight Holstein cattle milked 3 times per day were used in this study. After collecting a baseline milk sample, each cow received intramammary infusions of hetacillin in the left front and right rear quarters once a day for $3 \mathrm{~d}$. Milk samples from each of the treated quarters were collected at each milking and frozen until analysis. Milk samples were analyzed for ampicillin concentrations using an ultra-performance liquid chromatography method. All treated quarters had antibiotic concentrations well above the minimum inhibitory concentration (MIC) for gram-positive mastitis pathogens at 8 and $16 \mathrm{~h}$ postinfusion. Milk concentrations had fallen well below the MIC by the 24-h period (before the next infusion). All 8 cows in this study consistently had individual quarter milk ampicillin concentrations below the FDA tolerance of $0.01 \mu \mathrm{g} /$ $\mathrm{mL}(10 \mathrm{ppb})$ within $48 \mathrm{~h}$ of the last infusion. Based on this study, milk ampicillin concentrations exceed the minimum inhibitory concentration required to inhibit the growth of $90 \%$ of organisms $\left(\mathrm{MIC}_{90}\right)$ for at least $65 \%$ of the dosing interval, which is sufficient for oncedaily dosing with most cases of gram-positive mastitis. Therefore, intramammary hetacillin should be an effective treatment for the vast majority of gram-positive
\end{abstract}

Received August 6, 2014.

Accepted November 20, 2014.

${ }^{1}$ Corresponding author: Geoffrey_Smith@ncsu.edu mastitis pathogens when used according to label (once per day) in cows milked 3 times per day.

Key words: hetacillin, intramammary, pharmacokinetics, mastitis

\section{Short Communication}

Clinical mastitis remains a common problem in dairy cattle and causes significant losses in milk production, according to the USDA National Animal Health Monitoring System (NAHMS) Dairy 2007 study (USDA-APHIS, 2008). Data from this study conducted in 17 major dairy states found that the percentage of farms that treated cows with antibiotics for mastitis was $85.4 \%$ (USDA-APHIS, 2008). Several commercially available antibiotics used to treat routine mastitis pathogens are labeled for intramammary use and are generally intended for cows that are milked twice daily. According to data from the 2007 NAHMS survey, more than $92.5 \%$ of dairy operations milk cows twice a day (USDA-APHIS, 2008). However, a growing number of dairy producers are increasing their milking frequency from twice to 3 times per day $(\mathbf{3} \times)$ to improve milk production (Pearson et al., 1979; Smith et al., 2002; Hale et al., 2003). When producers treat mastitis in cows milked $3 \times$, it is difficult to know what the proper dosing interval for intramammary antibiotics should be to maintain adequate therapeutic drug concentrations in the mammary gland.

Hetacillin is a broad-spectrum intramammary antibiotic that is used to treat major mastitis causing pathogens, including Streptococcus agalactiae, Streptococcus dysgalactiae, Staphylococcus aureus, and Escherichia coli. It is approved in the United States for administration once every $24 \mathrm{~h}$ for a maximum of 3 treatments. Hetacillin is prepared by a reaction of ampicillin with acetone and when administered as an aqueous solution; hetacillin is rapidly converted back to ampicillin and acetone in the mammary gland. Ampicillin, as a $\beta$-lactam antibiotic, must be tested for in every tanker load of milk shipped for processing according to the Pasteurized Milk Ordinance (FDA, 2011). The more frequent milking associated with a $3 \times$ system, as well as the increased milk production, may dilute antimicro- 
bial concentrations in the mammary gland and enhance the clearance of the drug. Previous studies have shown that increasing milking frequency was accompanied by a more rapid elimination of $\beta$-lactam drugs, such as cefquinome and procaine penicillin (Knappstein et al., 2003). The amount of time the antibiotic concentration spends above the MIC of the bacterial pathogen being treated is critical for therapeutic success (Erskine et al., 2003). Therefore, from a clinical view, it is critical to generate pharmacokinetic data on intramammary antibiotics in cattle milked $3 \times$ to help determine appropriate dosing intervals for producers. Past studies demonstrated that milking frequency did not affect the length of time that milk drug concentrations exceeded the MIC values when intramammary cephapirin was administered to dairy cows (Stockler et al., 2009a; Gorden et al., 2013). However, no data exist on the pharmacokinetics of intramammary hetacillin in dairy cattle. The objective of our study was to evaluate whether once-daily intramammary infusion of hetacillin was sufficient to maintain therapeutic drug concentrations in cattle milked 3 times per day.

The study protocol was approved by the North Carolina State University Institutional Committee on the Care and use of Laboratory Animals. This study was done on a single dairy that milked approximately 200 cows. Cattle were housed in a freestall barn with sand bedding and were being milked 3 times per day. They were fed a corn silage-based TMR throughout the study period and fresh water was available ad libitum. All cows were at least $60 \mathrm{~d}$ into lactation and had not been treated for mastitis or administered any antimicrobials during their current lactation.

After collecting baseline milk samples, $62.5 \mathrm{mg}$ of hetacillin potassium (Hetacin-K, Boehringer Ingelheim Vetmedica, Inc., St Joseph, MO) was infused into the left front and right rear quarters of each cow after the morning milking. The full insertion method was used and the infused product was massaged into the udder after administration. Cows were milked at 0600, 1400, and $2200 \mathrm{~h}$ each day. For each milk sample, $20 \mathrm{~mL}$ of foremilk was collected into a tube, followed by an additional $20 \mathrm{~mL}$ of milk collected into the same tube after the cow had been milked out by machine. Milk samples were stored at $-20^{\circ} \mathrm{C}$ until analysis.

There are few analytical methods previously described that have used HPLC for analysis of antibiotics residues in bovine milk (Holstege et al., 2002). These methods are usually developed for multiple classes of antibiotics, allowing for milk samples to be screened for many different drug residues. The method described in the current study improves upon the low recovery percentage of ampicillin that is common in multidrug analysis and was validated in the Food Animal Residue Avoidance and Depletion Program Laboratory at North Carolina State University. Ultra-performance liquid chromatography triple quad (UPLC-MS-MS) using electrospray ionization operating in the positive mode was used to determine ampicillin concentrations in milk samples. Briefly, $2 \mathrm{~mL}$ of milk was transferred to a $15-\mathrm{mL}$ centrifuge tube. Two milliliters of acetonitrile was added and the sample was vortexed for $30 \mathrm{~s}$. The samples were then centrifuged at $3,500 \times g$ at $4^{\circ} \mathrm{C}$ for $7 \mathrm{~min}$. Two milliliters of supernatant was transferred to a new centrifuge tube and $3 \mathrm{~mL}$ of acidified acetonitrile with $0.2 \%$ formic acid was added. Samples were mixed for 30 $\mathrm{s}$ and again centrifuged at $3,500 \times g$ for $1 \mathrm{~min}$. Samples were then placed in a refrigerator $\left(2^{\circ} \mathrm{C}\right)$ overnight for $12 \mathrm{~h}$. One milliliter of resulting supernatant was then added to a SepPak C18 cartridge (Waters Corporation, Milford, MA) for cleanup. Cartridges were conditioned with 80:20 (vol/vol) acetonitrile to water and a $1-\mathrm{mL}$ sample was loaded onto the cartridge. Each sample was then washed with $1 \mathrm{~mL}$ of 80:20 acetonitrile to water and the resulting sample was dried under nitrogen for $90 \mathrm{~min}$. Samples were reconstituted in $200 \mu \mathrm{L}$ of mobile phase and injected onto class Acquity UPLC with a Xevo/TQD mass spectrometer (Waters Corporation). The limits of detection and quantification for ampicillin were 0.001 and $0.004 \mu \mathrm{g} / \mathrm{mL}$, respectively.

Data are presented as mean $\pm \mathrm{SD}$. Ampicillin concentrations at 8 and $16 \mathrm{~h}$ after infusion were compared with baseline concentrations using a one-way ANOVA. Values of $P<0.05$ were considered significant. A statistical software package was used to conduct the data analysis (SAS version 9.1, SAS Institute, Cary, NC).

Following intramammary infusion, ampicillin concentrations were increased $(P<0.001)$ in the milk of treated cows at 8 and $16 \mathrm{~h}$ as compared with baseline (Figure 1; Table 1). A large variation in ampicillin concentrations were seen in each quarter at each time point. However, ampicillin concentrations remained above 0.5 $\mu \mathrm{g} / \mathrm{mL}$ at the evening milking $(16 \mathrm{~h})$ on $\mathrm{d} 1$ and 2 and were above $1.0 \mu \mathrm{g} / \mathrm{mL}$ at $16 \mathrm{~h}$ postinfusion on $\mathrm{d}$ 3 , which is above the $\mathrm{MIC}_{90}$ for gram-positive mastitis pathogens. When comparing concentrations $24 \mathrm{~h}$ after dosing, none of the quarters had drug concentrations above the MIC for any pathogen for an entire 24-h period. Milk concentrations of ampicillin had depleted below the tolerance limit of $0.01 \mu \mathrm{g} / \mathrm{mL}$ within $48 \mathrm{~h}$ of the last infusion and remained below that level for the rest of the study (Table 1).

For this project, we selected an MIC for ampicillin of $0.25 \mu \mathrm{g} / \mathrm{mL}$. This number was primarily based on 2 recent publications examining the susceptibility of a large number of mastitis pathogens (Lindeman et al., 2013; Pol and Ruegg, 2007). In these studies, the antimicrobial susceptibility patterns of 8,500 mastitis 


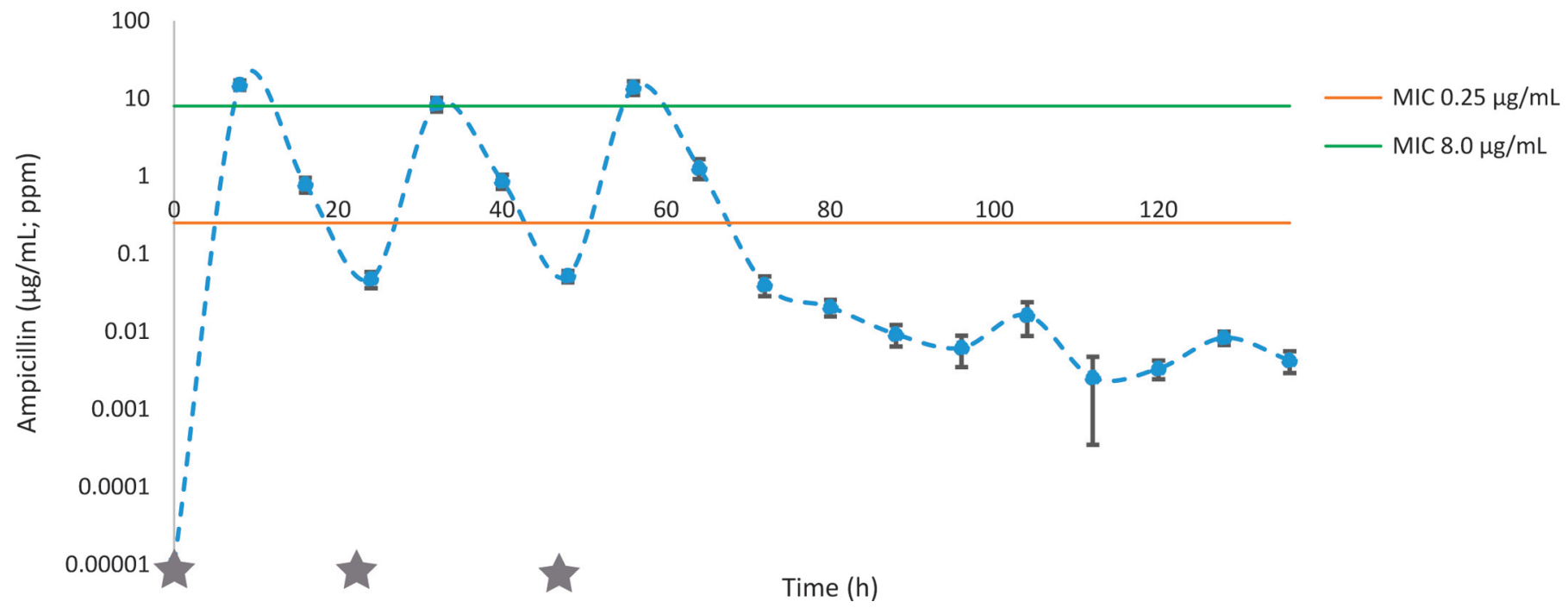

Figure 1. Ampicillin concentrations at each milking $(3 \times$ daily $)$ for left front and right rear quarters of each cow after administration of Hetacin-K (Boehringer Ingelheim Vetmedica Inc., St Joseph, MO) intramammary (IMM) into 2 quarters once a day for $3 \mathrm{~d}(\mathrm{n}=16)$. Star $=$ IMM treatment administered. Color version available online.

pathogens were examined. These isolates came from 25 different veterinary diagnostic laboratories across the United States and were collected between 2002 and 2010 (Table 2). In both studies, the $\mathrm{MIC}_{90}$ for all pathogens examined was either 0.12 or $\leq 0.25 \mu \mathrm{g} / \mathrm{mL}$, with the exception of Streptococcus uberis (where 85.5\% of isolates fell at or under this target) and Staph. aureus (where $84.5 \%$ of isolates were at or below $0.25 \mu \mathrm{g} / \mathrm{mL}$ ). The current breakpoints for ampicillin as established by Clinical and Laboratory Standards Institute (CLSI, 2007) for these pathogens in humans are $0.25 \mu \mathrm{g} / \mathrm{mL}$ for Staph. aureus, as well as Strep. agalactiae and Strep. dysgalactiae. Based on the referenced studies, the established CLSI breakpoints appear reasonably accurate for gram-positive mastitis pathogens, which would be the predominant target of hetacillin use in the majority of cases. Therefore, we used an ampicillin concentration of $0.25 \mu \mathrm{g} / \mathrm{mL}$ as a target level in milk when examining the data from the current study. It should be noted, however, that in the survey by Lindeman et al. (2013), which looked at mastitis isolates over a 9-yr period, $14 \%$ of Strep. uberis isolates had an MIC of $0.5 \mu \mathrm{g} / \mathrm{mL}$. Therefore it could be argued that $0.5 \mu \mathrm{g} / \mathrm{mL}$ would be a more appropriate $\mathrm{MIC}_{90}$ target for this pathogen.

Table 1. Ampicillin concentrations in milk collected from the left front and right rear quarters of cows infused with Hetacin-K (Boehringer Ingelheim Vetmedica Inc., St Joseph, MO) once every 24 h for $3 \mathrm{~d}^{1}$

\begin{tabular}{llcc}
\hline Day & Time & $\begin{array}{c}\text { Left front } \\
\text { quarters }\end{array}$ & $\begin{array}{c}\text { Right rear } \\
\text { quarters }\end{array}$ \\
\hline 1 & 0 (before infusion) & 0 & 0 \\
& $8 \mathrm{~h}$ & $13.5 \pm 3.0$ & $16.3 \pm 2.7$ \\
2 & $16 \mathrm{~h}$ & $0.87 \pm 0.27$ & $0.69 \pm 0.21$ \\
& $8 \mathrm{~h}$ & $0.049 \pm 0.019$ & $0.04 \pm 0.01$ \\
& $16 \mathrm{~h}$ & $5.2 \pm 1.9$ & $11.3 \pm 2.9$ \\
3 & 0 (before infusion) & $0.83 \pm 0.22$ & $0.90 \pm 0.29$ \\
& $8 \mathrm{~h}$ & $0.05 \pm 0.015$ & $0.04 \pm 0.008$ \\
4 & $16 \mathrm{~h}$ & $15.2 \pm 4.4$ & $12.4 \pm 3.4$ \\
& $8 \mathrm{~h}$ & $1.09 \pm 0.94$ & $1.47 \pm 0.68$ \\
& $16 \mathrm{~h}$ & $0.028 \pm 0.007$ & $0.051 \pm 0.021$ \\
& 0 & $0.019 \pm 0.008$ & $0.021 \pm 0.005$ \\
& $8 \mathrm{~h}$ & $0.008 \pm 0.002$ & $0.01 \pm 0.005$ \\
6 & $16 \mathrm{~h}$ & $0.015 \pm 0.011$ & $0.008 \pm 0.004$ \\
& $8 \mathrm{~h}$ & $0.003 \pm 0.001$ & $0.017 \pm 0.010$ \\
& $16 \mathrm{~h}$ & $0.003 \pm 0.001$ & $0.004 \pm 0.002$ \\
& & $0.007 \pm 0.001$ & $0.003 \pm 0.0009$ \\
& & $0.0003 \pm 0.001$ & $0.009 \pm 0.003$ \\
& & & $0.005 \pm 0.002$ \\
\hline
\end{tabular}

${ }^{1}$ All cows $(n=8)$ in this study were milked 3 times per day. Concentrations are expressed in $\mu \mathrm{g} / \mathrm{mL}$ as mean \pm SE. 
Table 2. Ampicillin MIC from selected mastitis isolates in 2 field studies

\begin{tabular}{|c|c|c|c|c|c|c|}
\hline \multirow[b]{2}{*}{ Item } & \multirow{2}{*}{$\begin{array}{c}\text { No. of } \\
\text { isolates }\end{array}$} & \multicolumn{5}{|c|}{$\begin{array}{l}\text { Percentage of isolates susceptible at each indicated MIC } \\
\qquad(\mu \mathrm{g} / \mathrm{mL})\end{array}$} \\
\hline & & 0.12 & 0.25 & 0.5 & 1.0 & $\geq 2.0$ \\
\hline \multicolumn{7}{|l|}{ Pol and Ruegg, 2007} \\
\hline Staphylococcus aureus & 130 & 95.6 & 0.6 & 3.8 & 0 & 0 \\
\hline CNS & 267 & 90.4 & 3.0 & 4.1 & 1.4 & 1.1 \\
\hline Streptococci $^{1}$ & 95 & 91.8 & 7.1 & 0 & 0 & 1.2 \\
\hline & & 0.06 & 0.12 & 0.25 & 0.5 & $\geq 1.0$ \\
\hline \multicolumn{7}{|l|}{ Lindeman et al., 2013} \\
\hline Streptococcus agalactiae & 505 & 40.4 & 56.7 & 2.8 & & \\
\hline Streptococcus dysgalactiae & 1,627 & 95.9 & 2.1 & 1.8 & & \\
\hline Streptococcus uberis & 1,623 & 22.2 & 13.9 & 49.4 & 13.9 & 0.6 \\
\hline Staphylococcus aureus & 2,181 & 44.2 & 36.2 & 4.1 & 3.2 & 12.3 \\
\hline
\end{tabular}

${ }^{1}$ These were environmental streptococcal mastitis pathogens (nonagalactiae).

In the same study, $84.5 \%$ of the Staph. aureus isolates had an MIC $\leq 0.25 \mu \mathrm{g} / \mathrm{mL}, 3.2 \%$ had an MIC of 0.5 , and $12.3 \%$ had MIC values $\geq 1.0 \mu \mathrm{g} / \mathrm{mL}$. Based on this data, approximately $15 \%$ of Staph. aureus isolates would have MIC values higher than the $0.25 \mu \mathrm{g} / \mathrm{mL}$ we chose as a target in the current study.

The current CLSI breakpoint for E. coli is $8 \mu \mathrm{g} / \mathrm{mL}$. In previous research, the concentration that inhibits $50 \%$ of bacterial concentrations for E. coli isolates ranged between 2 and $4 \mu \mathrm{g} / \mathrm{mL}$, whereas $\mathrm{MIC}_{90}$ concentrations were $>8 \mu \mathrm{g} / \mathrm{mL}$ (Pol and Ruegg, 2007; Lindeman et al., 2013). However, ampicillin concentrations were consistently above $8 \mathrm{ug} / \mathrm{mL}$ at $8 \mathrm{~h}$ after dosing (Table 1 ), but they were well below $2 \mu \mathrm{g} / \mathrm{mL}$ by $16 \mathrm{~h}$. This data would suggest that if intramammary hetacillin was going to be used to treat $E$. coli mastitis it would likely need to be administered every $16 \mathrm{~h}$, which is more frequently than approved by the product label.

When creating dosing regimens (intervals) for $\beta$-lactam antibiotics, it is generally accepted that concentrations in the blood or target tissue should be above the MIC for 50 to $60 \%$ of the dosing interval in patients that are not immunocompromised (Turnidge, 1998; Toutain et al., 2002; Papich, 2014). These recommendations have not yet been validated for mastitis therapy, however, and may or may not be accurate. In a review, Whittem et al. (2012) described that, due to typical milking practices, measuring milk drug concentrations usually occur at infrequent intervals of 8 , 12, or $24 \mathrm{~h}$. These infrequent intervals provide sparse and intermittent milk drug concentration data that are inadequate for usual pharmacokinetic modeling approaches. To sample at time points more frequent than milking interval is also inappropriate because sampling of the milk most probably influences the rate of drug elimination, as sample collection can initiate milk let down and influence drug concentrations. Therefore, we elected to sample only at 8 -h intervals in the current study, mimicking the normal milking times in $3 \times$ herds. Based on our study, milk ampicillin concentrations are above an $\mathrm{MIC}_{90}$ of either 0.25 or $0.5 \mu \mathrm{g} / \mathrm{mL}$ for at least $16 \mathrm{~h}$ in dairy cows milked $3 \times$ (Table 1 ). Ampicillin concentrations on d 1 and 2 were very close to $1.0 \mu \mathrm{g} / \mathrm{mL}$ $16 \mathrm{~h}$ after dosing and exceeded this concentration on $\mathrm{d}$ 3 . Erskine et al. (2003) determined that the concentration of $\beta$-lactams in the udder should be maintained for at least half the duration of the dosing. When hetacillin is used every $24 \mathrm{~h}$ as per the label directions, this would suggest that ampicillin concentrations exceeded the MIC for at least $65 \%$ of the dosing interval in most cases. Therefore, when cows are being milked 3 times per day, our study would indicate that hetacillin should still be given once every $24 \mathrm{~h}$. Future studies would be needed with samples taken at different time points to determine exactly how long ampicillin concentrations are maintained above an MIC concentration of 0.25 or $0.5 \mu \mathrm{g} / \mathrm{mL}$.

One potential confounder in our study is the milk fraction collected for analysis. Previous research has demonstrated that cephapirin concentrations were higher in foremilk than in bucket milk or strippings (leftover milk in the quarter after a cow has finished milking). In 6 cows infused with intramammary cephapirin after 2 milkings, drug concentrations averaged $44.2 \mu \mathrm{g} / \mathrm{mL}$ in foremilk, $15.7 \mu \mathrm{g} / \mathrm{mL}$ in bucket milk, and $18.5 \mu \mathrm{g} / \mathrm{mL}$ in the strippings (Stockler et al., 2009b). Thus, the use of foremilk for pharmacokinetics analysis may overestimate drug concentrations in the mammary gland. In the study with cephapirin, strippings were more representative of bucket milk than foremilk and foremilk overestimated true bucket milk concentrations by 2-fold (Stockler et al., 2009b). In our study, we chose to use a mixture of foremilk and strippings to more closely approximate the drug concentration 
present in the mammary gland. Pooled milk samples from the entire mammary gland used in residue studies are inappropriate for estimation of individual quarter milk drug concentrations unless the drug is administered parenterally. Therefore, when treating individual quarters, true bucket milk samples would necessitate collecting the milk from each individual quarter separately during milking, which can be difficult. Although the previous study with cephapirin (Stockler et al., 2009b) found that the collection of strippings was likely to be a more appropriate sample for pharmacokinetic studies than foremilk, we could not consistently get an adequate volume of milk for analysis from strippings alone. Therefore, we decided to use an equal volume of foremilk and strippings. Although differences in the distribution of different drugs into milk fractions may exist and a difference in drug distribution related to increased frequency of milking may have occurred, the use of foremilk and strippings for analysis may lead to an overestimation of ampicillin concentrations in the milk when compared with actual bucket milk concentrations. The relationship between milk fraction and antimicrobial concentration should be investigated in future research efforts.

With the increasing frequency of dairy farms milking 3 times per day and with the popularity of automated milking systems in the United States and European Union, increasing interest on how milking frequency effects the distribution and elimination of intramammary drugs has been observed. In a study using intramammary cephapirin, cows dosed at a $16-\mathrm{h}$ interval maintained antibiotic concentrations for a longer period of time than cows dosed at an 8-h interval in Holsteins that were milked $3 \times$ per day (Stockler et al., 2009a). Frequency of intramammary treatment in that study had no effect on milk withdrawal intervals, which correlated well with the results of the present study.

Research has indicated that the effect of increased milking frequency on drug elimination is dependent on which antibiotic is used. For example, one study (Knappstein et al., 2003) showed that the time for penicillin to fall short of the maximum residue limit increased with decreased milking frequency (clearance was delayed in cows milked 1.5 or $2 \times$ per day as compared with cows milked 3 times per day). In contrast, when cefquinome was used, the difference in clearance rates between individual cows had significantly more influence on elimination than milking frequency (Knappstein et al., 2003). A follow-up study was conducted by the same research group using a greater number of drugs. The results showed that, in general, shorter excretion periods were seen with increased milking frequency; however, differences in drug elimination times were dependent on the antibiotic used, the dosage, and drug formulation as well as the individual cow (Knappstein et al., 2005).

Another factor to consider that could potentially affect drug concentrations in bovine milk is the proportion of ionized and unionized drug in milk. The $\mathrm{pH}$ of milk can range anywhere from 6.4 to 7.0 and is mildly acidic compared with plasma, which has an average $\mathrm{pH}$ of 7.4. In clinical mastitis cases, milk pH often increases with mastitis (Bansal et al., 2005). Hetacillin, once converted to ampicillin in vivo, becomes an amphoteric drug, with 2 possible pKa values, making the ability to measure the unbound drug in intramammary formulations quite complicated (Gehring and Smith, 2006). Milk $\mathrm{pH}$ is one factor that may change the ionization of certain intramammary drugs in cows with mastitis, but was not examined in the current study that used clinically healthy animals.

All 8 cows in this study consistently had individual quarter milk ampicillin concentrations below the FDA tolerance of $0.01 \mu \mathrm{g} / \mathrm{mL}$ within $48 \mathrm{~h}$ of the last infusion. This is somewhat faster than the current withdrawal time of $72 \mathrm{~h}$ (6 milkings) and might suggest that more frequent milking results in faster elimination of the drug from the mammary gland. The data available would indicate that increasing milking frequency certainly does not appear to prolong drug elimination (i.e., there is no need for increased withdrawal times); therefore, veterinarians and producers are encouraged to follow the withholding periods recommended by the label of each drug.

When intramammary hetacillin is dosed every $24 \mathrm{~h}$, as per the label directions, our study indicated that ampicillin concentrations would exceed $0.5 \mu \mathrm{g} / \mathrm{mL}$ for at least 16 out of $24 \mathrm{~h}$ in the dosing interval. Therefore, this data supports the administration of intramammary hetacillin once every $24 \mathrm{~h}$, which should be effective for the treatment of most gram-positive mastitis pathogens in cows milked 3 times a day. The current study also developed a new sample extraction method that allows for much higher recoveries of hetacillin at even lower limit of detection as compared with previous multidrug residue methods.

\section{ACKNOWLEDGMENTS}

The authors thank Boehringer Ingelheim Vetmedica Inc. (St. Joseph, MO) for supplying the hetacillin and funding for this project. We also thank the staff at the Lake Wheeler Dairy at North Carolina State University for their help with milk sample collections and Jennifer Davis, Jenna Shrimer, and Jim Yeatts of the Food Animal Residue Avoidance Depletion Program at North Carolina State University for their help in assay development. 


\section{REFERENCES}

Bansal, B. K., J. Hamann, N. Grabowskit, and K. Singh. 2005. Variation in the composition of selected milk fraction samples from healthy and mastitic quarters, and its significance for mastitis diagnosis. J. Dairy Res. 72:144-152.

Clinical Laboratory and Standards Institute (CLSI). 2007. Performance standards for antimicrobial susceptibility testing. M100S17. CLSI, Wayne, PA.

Erskine, R. J., S. Wagner, and F. J. DeGraves. 2003. Mastitis therapy and pharmacology. Vet. Clin. North Am. Food Anim. Pract. 19:109-138.

Food and Drug Administration. 2011. Grade A Pasteurized Milk Ordinance. Accessed Dec. 15, 2014. http://www.fda.gov/downloads/ food/guidanceregulation/ucm291757.pdf.

Gehring, R., and G. W. Smith. 2006. An overview of factors affecting the disposition of intramammary preparations used to treat bovine mastitis. J. Vet. Pharmacol. Ther. 29:237-241.

Gorden, P. J., M. van der List, F. D. Lehman, R. K. Lantz, and P. D. Constable. 2013. Elimination kinetics of cephapirin sodium in milk after an 8-day extended therapy program of daily intramammary infusion in healthy lactating Holstein-Fresian cows. J. Dairy Sci. 96:4455-4464.Hale, S. A., A. V. Capuco, and R. A. Erdman. 2003. Milk yield and mammary growth effects due to increased milking frequency during early lactation. J. Dairy Sci. 86.2061-2071.

Holstege, D. M., B. Puschner, G. Whitehead, and F. D. Galey. 2002. Screening and mass spectral confirmation of $\beta$-lactam antibiotic residues in milk using LC-MS/MS. J. Agric. Food Chem. 50:406411.

Knappstein, K., G. Suhren, and H. G. Walte. 2003. Influence of milking frequency on withdrawal period after application of beta-lactam antibiotic-based drugs. Anal. Chim. Acta 483:241-249.

Knappstein, K., G. Suhren, and H. G. Walte. 2005. Influences on excretion of antibiotic residues in milk with special emphasis on milking frequency. Pages 677-683 in Proc. 4th Int. Dairy Fed. Intl. Mastitis Conf., Maastricht, the Netherlands. Wageningen Academic Publishers, Wageningen, the Netherlands.
Lindeman, C. J., E. Portis, L. Johansen, L. M. Mullins, and G. A. Stoltman. 2013. Susceptibility to antimicrobial agents among bovine mastitis pathogens isolated from North American dairy cattle, 2002-2010. J. Vet. Diagn. Invest. 25:581-591.

Papich, M. G. 2014. Pharmacokinetic-pharmacodynamic (PK-PD) modeling and the rational selection of dosage regimes for the prudent use of antimicrobial drugs. Vet. Microbiol. 171:480-486.

Pearson, R. E., L. A. Fulton, P. D. Thompson, and J. W. Smith. 1979. Three times a day milking during the first half of lactation. J. Dairy Sci. 62:1941-1950.

Pol, M., and P. L. Ruegg. 2007. Relationship between antimicrobial drug usage and antimicrobial susceptibility of Gram-positive mastitis pathogens. J. Dairy Sci. 90:262-273.

Smith, J. W., L. O. Ely, W. M. Graves, and W. D. Gilson. 2002. Effect of milking frequency on DHI performance measures. J. Dairy Sci. 85:3526-3533.

Stockler, R. M., D. E. Morin, R. K. Lantz, and P. D. Constable. 2009a. Effect of milking frequency and dosing interval on the pharmacokinetics of cephapirin after intramammary infusion in lactating cows. J. Dairy Sci. 92:4262-4275.

Stockler, R. M., D. E. Morin, R. K. Lantz, W. L. Hurley, and P. D. Constable. 2009b. Effect of milk fraction on concentrations of cephapirin and desacetylcephapirin in bovine milk after intramammary infusion of cephapirin sodium. J. Vet. Pharmacol. Ther. 32:345-352.

Toutain, P. L., J. R. del Castillo, and A. Bousquet-Mélou. 2002. The pharmacokinetic-pharmacodynamic approach to a rational dosage regimen for antibiotics. Res. Vet. Sci. 73:105-114.

Turnidge, J. D. 1998. The pharmacodynamics of $\beta$-lactams. Clin. Infect. Dis. 27:10-22.

USDA-APHIS (Animal Plant Health Inspection Service). 2008. Antibiotic use on US dairy operations, 2002 and 2007. Accessed Jun. 10, 2014. http://www.aphis.usda.gov/animal_health/nahms/ dairy/downloads/dairy07/Dairy07_is_AntibioticUse.pdf.

Whittem, T., J. H. Whittem, and P. D. Constable. 2012. Modelling the concentration-time relationship in milk from cattle administered an intramammary drug. J. Vet. Pharmacol. Ther. 35:460-471. 